International Journal of Linguistics, Literature and Culture
Available online at https://sloap.org/journals/index.php/ijllc/
Vol. 8, No. 1, January 2022, pages: 1-5
ISSN: 2455-8028
https://doi.org/10.21744/ijllc.v8n1.2003

\title{
Mastering a Second Language as a Theoretical and Linguodidactic Problem in the Aspect of Neuro-Linguistics
}

Kenjayeva Adolat Asrorovna ${ }^{a}$

Article history:

Submitted: 27 October 2021

Revised: 09 November 2021

Accepted: 15 December 2021

\section{Keywords:}

linguodidactic problems; non-native language; second foreign language; neurolinguistic;

teaching;

\begin{abstract}
This article arose from the need to comprehend, firstly, methodological and linguodidactic problems (by linguodidactics we understand the principles of language description for learning purposes) to mastering any non-native language, not only widespread foreign languages, and, secondly, from the need to comprehend not only the teaching of a second foreign language itself but also the content of training professionals of a second foreign language (students of universities and faculties of foreign languages). Theoretical and methodological problems associated with mastering any non-native language are especially acute when we are dealing not with the first, but with the second, third, etc. non-native language. This may be a second foreign language (for example, at school), a second foreign language as the language of a pedagogical specialty (for example, at a pedagogical university), the language of ethnic (self) identification (among members of national diasporas), etc. Therefore, in this paper, along with discussing general issues of mastering a non-native language, we focus on various situations of teaching a language as a second non-native.
\end{abstract}

International journal of linguistics, literature and culture () 2022. This is an open access article under the CC BY-NC-ND license (https://creativecommons.org/licenses/by-nc-nd/4.0/).

Corresponding author:

Kenjayeva Adolat Asrorovna,

Teacher, Translation department, UzSWLU, Tashkent, Uzbekistan.

Email address: adolatkenjaeva@gmail.com

a Translation department, UzSWLU, Tashkent, Uzbekistan 


\section{Introduction}

English is currently a typical second foreign language in the education system in Uzbekistan, and its material can show many problems associated with a second foreign language in general and partly with any foreign language (Teng \& Zhang, 2020; Henry \& Apelgren, 2008). The phenomenon of quasi-communication or pseudocommunication in foreign language lessons is analyzed, and the associated widespread inability of students to conduct a meaningful analysis of a foreign language text. Theoretically, a student of a special faculty of a language university, whom we train as a teacher of two foreign languages, it would seem, should be equally prepared in both languages (Gafiiatova, 2015; Nechayev, 2014). Meanwhile, this is not always true. Linguodidactic problematics, i.e. ways and means of improving the description of a particular language to teach it as a non-native language, is a necessary condition and an organic component of the theory of mastering a non-native language (Clahsen \& Felser, 2006; Perrachione \& Wong, 2007). If mastering a foreign language can be considered as a movement from "my" language to "someone else's", then in cases where a particular language is the language of ethnic self-identification, but not the native language of students, one can figuratively talk about the path from "my" language to "ours" (Abegyan, 1965; Thomson, 2013; Avrorin, 1975).

\section{Materials and Methods}

As a rule, the description of a non-native language for teaching purposes acts as a synthesis of active (onomasiological) and passive (semasiological) approaches according to JI.B. Shcherba and V.G. Gak. Such a description should be based on a universally comparative typological approach (M.M. Bakhtin, S.I. Bernstein, A.A. Leontiev). The basis of the universal-comparative description is the distinction between the system of functional means of a given language and the system of methods or techniques for constructing statements in this language (Baryshnikov, 2004; Bondarko, 1999; Halperin, 1966). The minimum description program of a particular language to teach it as a non-native language should include the following components:

a) descriptions of language tools;

b) descriptions of ways of expressing communicative-speech intentions (in onomasiological terms);

c) description of the ways of expressing the most general content categories in this language (in onomasiological terms);

d) main lexical topics;

e) the main features of culture and communication.

Unfortunately, the analysis of really existing textbooks and self-help books of the languages of Uzbekistan and the CIS countries shows their linguistic and didactic incompleteness, weak didactic orientation, and the practical absence of methodological apparatus in them. Mastering a second and generally non-native language can go in different ways (Locke, 1997; Grosjean, 1989). This may be spontaneous language acquisition through practical communication in a language environment or language acquisition through its special study, usually taking place in institutionalized forms (school, university, courses). The intersection of both paths is also possible. But if the process of language learning (as the creation of conditions for mastering it) is well understood by methodologists to various forms of learning, then the strategies of this mastery itself have not been sufficiently studied. There is a problem of theoretical understanding of the ways and means leading to the mastery of a non-native language (Caldwell-Harris \& AyçiçeğiDinn, 2009).

Speaking of a non-native language, we mean both a foreign language (usually a world language or any other common language studied in an institutionalized form) and any other language, the need to master which is associated with socio-political, professional, personal reasons. For example, Uzbek is taught in schools and universities of Uzbekistan as the state language (the language of interethnic communication). In many regions of the country, the subject of study is the titular languages of the republics within Uzbekistan and even just languages of interethnic communication that do not have official status. On the other hand, many representatives of national diasporas tend to learn the language of their ethnic group, although it is not their native language.

Thus, the process of mastering various non-native languages (not to mention the process of mastering a nonnative language in a language environment) assumes, along with specific features characteristic, for example, of mastering a foreign language, some general theoretical patterns and the resulting methodological methods and 
techniques that are not closed to a specific form of learning and a certain type of language taught. In other words, there is a need to build a general theory of mastering a non-native language, which would be a support for the development of specific methods of teaching various languages in various forms of education (Vescio et al., 2008; Hoy \& Spero, 2005).

In this regard, it should be emphasized that the process of language acquisition itself (in an institutionalized form) following modern trends in pedagogy and pedagogical psychology is increasingly interpreted as a two-way reciprocal activity of the teacher and the student. I.e., the theory of mastering a non-native language cannot but focus on the active activity of the student in language acquisition, on the implementation of the student's characteristics in this process, and the idea of the priority of the student's strategy over the strategies of the teacher (student autonomy).

In the light of what has been said, it is obvious that the theory of mastering a non-native language should be essentially interdisciplinary. It assumes, on the one hand, a certain general psychological and general didactic approach and, thus, fits into the ideas of the so-called developmental education. On the other hand, it assumes a broad account of the data and theoretical provisions of the methodology of teaching foreign languages (Shomirzayev, 2021). On the third hand, orientation to the creative activity of the student himself requires reference to the data of general, age, and pedagogical psychology (Halperin, 1966; Vereshchagin, 2014; Gack, 2004).

At the same time, the construction of a theory of mastering a non-native language requires the inclusion of a scientific field in it, the importance of which is underestimated. We are talking about the problems of linguodidactics as a theory of constructing models for describing the language being studied, intended for use in the educational process. It is in this regard that taking into account the experience and problems of mastering non-native languages can enrich not only the general theory of language acquisition but also the methodology of teaching foreign languages based on it (Kumar et al., 2016).

The construction of a general theory of language acquisition, however, encounters from the very beginning numerous difficulties associated with the ambiguity of the conceptual system used, sometimes reaching almost the opposite interpretation of the same terms and concepts. Even such seemingly obvious concepts as "native language", "second language", "bilingualism" (bilingualism), etc., do not have any generally accepted interpretation. The formation of bilingualism at the present stage is carried out in the conditions of rapid social and scientific and technological progress, which largely determines both the current state of languages and their movement into the future. In turn, languages act as a means and incentive for social and scientific, and technological progress. This reflects the dialectical nature of the relationship between language and society.

Currently, the object of bilingualism is divided between psycholinguistics, sociolinguistics, and linguistics proper. The sociolinguistic aspect of language interaction reveals the causes of bilingualism, psycholinguistics is the mechanism of language interaction, and the linguistic aspect is related to the consideration of the results of language contact. Without denying the rights of each of the listed sciences to its subject of research, it should be noted that a single object is voluntarily or involuntarily dissected and it is difficult to imagine it as a whole. This approach could be called isolating. There is an integrated approach, when one aspect is dominant (most often psychological), and the rest are subordinate. An integrated (or integrative) consideration of bilingualism from the point of view of the social organization of society and the mechanisms of socialization is also possible. Such a paradigm can be implemented within the framework of the structural concept of bilingualism, which the dissertation is trying to substantiate in this study.

\section{Results and Discussions}

The concept of "sociology of bilingualism" as a conditional designation of a particular section of sociology was introduced by E. M. Vereshchagin in the work mentioned above. Emphasizing that the classification of the phenomenon along this line can be very diverse, he proposed a sociological typology of bilingualism according to two criteria:

1) correlation of bilingualism as a skill with a group of speakers (individual, group, and mass bilingualism);

2) the method of mastering the skill (natural, artificial and synthesized, or intermediate, bilingualism). However, in the future, this direction did not find a sufficiently complete embodiment.

Optimization of the process of mastering a non-native language involves several directions. Firstly, it is the creation of psychologically comfortable conditions for the development and use of individual strategies for language

Asrorovna, K. A. (2022). Mastering a second language as a theoretical and linguodidactic problem in the aspect of neuro-linguistics. International Journal of Linguistics, Literature and Culture, 8(1), 1-5. https://doi.org/10.21744/ijllc.v8n1.2003 
acquisition and for the removal of psychologically uncomfortable learning conditions. In this sense, K. Vogel's attempt to outline the "ideal student model" is interesting, which in essence corresponds to the final (educational) goals of psychological optimization of the mastering process to a specific student. Secondly, this is the problem of presenting the material in an optimal form for mastering. Here in turn there are two lines:

a) linguodidactic - a description of the language system to teach it as a non-native, i.e. creating an indicative basis for assimilation according to P.Ya. Galperin and preparing the material following the laws of the process of internalization;

b) psychological and didactic how we optimally carry out this process of interiorization and how we bring interiorized language proficiency into the real situation of language functioning, which corresponds in the methodology to the problem of skills and the problem of communicative skills, respectively.

The study of the sociology of bilingualism is also of practical importance since its results can be used in the implementation of an adequate language and national policy.

\section{Conclusion}

Theoretical and methodological problems associated with mastering any non-native language are especially acute when we are dealing not with the first, but with the second, third, etc. non-native language. This may be a second foreign language (for example, at school), a second foreign language as the language of a pedagogical specialty (for example, at a pedagogical university), the language of ethnic (self) identification (among members of national diasporas), etc. Therefore, in this paper, along with discussing general issues of mastering a non-native language, we focus on various situations of teaching a language as a second non-native.

\section{Conflict of interest statement}

The author declared that she have no competing interest.

Statement of authorship

The author has a responsibility for the conception and design of the study. The author has approved the final article.

\section{Acknowledgments}

I am grateful to two anonymous reviewers for their valuable comments on the earlier version of this paper. 


\section{References}

Abegyan, M. (1965). Theory of the Armenian language. Er., 1931; 2nd ed., Yerevan, 1965 (in Armenian).

Avrorin, V.A. (1975). Problems of studying the functional side of the language: (On the question of the subject of sociolinguistics). The science. Leningrad. separation.

Baryshnikov, N.V. (2004). Teaching multilingualism: principles and technologies. Sat. scientific. articles. Taganrog, 26-34.

Bondarko, A. V. (1999). Fundamentals of functional grammar. Autonomous non-profit organization "Publishing House of St. Petersburg State University".

Caldwell-Harris, C. L., \& Ayçiçeği-Dinn, A. (2009). Emotion and lying in a non-native language. International Journal of Psychophysiology, 71 (3), 193-204. https://doi.org/10.1016/j.ijpsycho.2008.09.006

Clahsen, H., \& Felser, C. (2006). How native-like is non-native language processing?. Trends in cognitive sciences, 10(12), 564-570. https://doi.org/10.1016/j.tics.2006.10.002

Gack, W.G. (2004). Theoretical grammar of the French language. Good light. $832 \mathrm{~s}$.

Gafiiatova, E. (2015). Bridging languages in agriculture and forestry translation studies academic courses. ProcediaSocial and Behavioral Sciences, 199, 402-406. https://doi.org/10.1016/j.sbspro.2015.07.525

Grosjean, F. (1989). Neurolinguists, beware! The bilingual is not two monolinguals in one person. Brain and language, 36(1), 3-15. https://doi.org/10.1016/0093-934X(89)90048-5

Halperin, P. Ya. (1966). Psychology of thinking and the doctrine of the gradual formation of mental actions. Research of thinking in Soviet psychology / Ed. EV Shorokhovoy. - M .: published in APN SSR, 132.

Henry, A., \& Apelgren, B. M. (2008). Young learners and multilingualism: A study of learner attitudes before and after the introduction of a second foreign language to the curriculum. System, 36(4), 607-623. https://doi.org/10.1016/j.system.2008.03.004

Hoy, A. W., \& Spero, R. B. (2005). Changes in teacher efficacy during the early years of teaching: A comparison of four measures. Teaching and teacher education, 21(4), 343-356. https://doi.org/10.1016/j.tate.2005.01.007

Kumar, S. S., Kumar, R. S., \& Sankar, G. (2016). Creative thinking of English language teaching to the secondary language learners. International Journal of Linguistics, Literature and Culture, 2(4), 150-155.

Locke, J. L. (1997). A theory of neurolinguistic development. Brain and language, 58(2), 265-326. https://doi.org/10.1006/brln.1997.1791

Nechayev, N. N. (2014). Psychological Patterns of Development of Students' Secondary Language Personality. Procedia-Social and Behavioral Sciences, 154, 14-22. https://doi.org/10.1016/j.sbspro.2014.10.105

Perrachione, T. K., \& Wong, P. C. (2007). Learning to recognize speakers of a non-native language: Implications for the functional organization of human auditory cortex. Neuropsychologia, 45(8), 1899-1910. https://doi.org/10.1016/j.neuropsychologia.2006.11.015

Shomirzayev, S. (2021). National followers in the students use of educational technologies instruction of interests. International Journal of Linguistics, Literature and Culture, 7(3), 152-157. https://doi.org/10.21744/ijllc.v7n3.1508

Teng, L. S., \& Zhang, L. J. (2020). Empowering learners in the second/foreign language classroom: Can selfregulated learning strategies-based writing instruction make a difference?. Journal of Second Language Writing, 48, 100701. https://doi.org/10.1016/j.jslw.2019.100701

Thomson, A.I. (2013). Historical grammar of the modern Armenian language of the city of Tiflis. DirectMedia LLC.

Vereshchagin, E. M. (2014). Psychological and methodological characteristics of bilingualism (bilingualism). Directmedia.

Vescio, V., Ross, D., \& Adams, A. (2008). A review of research on the impact of professional learning communities on teaching practice and student learning. Teaching and teacher education, 24(1), 80-91. https://doi.org/10.1016/j.tate.2007.01.004

Asrorovna, K. A. (2022). Mastering a second language as a theoretical and linguodidactic problem in the aspect of neuro-linguistics. International Journal of Linguistics, Literature and Culture, 8(1), 1-5. https://doi.org/10.21744/ijllc.v8n1.2003 